\title{
Silencing of Foxp3 enhances the antitumor efficacy of GM-CSF genetically modified tumor cell vaccine against $\mathrm{B} / 6$ melanoma
}

This article was published in the following Dove Press journal:

OncoTargets and Therapy

23 January 2017

Number of times this article has been viewed

\author{
Antonio Miguel' \\ Luis Sendra' \\ Verónica Noé2 \\ Carles J Ciudad ${ }^{2}$ \\ Francisco Dasi $i^{3,4}$ \\ David Hervas ${ }^{5}$ \\ María José Herrero ${ }^{1,6}$ \\ Salvador F Aliño $0^{1,7}$ \\ 'Department of Pharmacology, Faculty \\ of Medicine, University of Valencia, \\ ${ }^{2}$ Department of Biochemistry \\ and Molecular Biology, Faculty of \\ Pharmacy, University of Barcelona, \\ ${ }^{3}$ Research University Hospital of \\ Valencia, INCLIVA Health Research \\ Institute, ${ }^{4}$ Department of Physiology, \\ Faculty of Medicine, University of \\ Valencia Foundation, ${ }^{5}$ Biostatistics \\ Unit, ${ }^{6}$ Pharmacogenetics Unit, \\ Instituto de Investigación Sanitaria La \\ Fe (IIS La Fe), ${ }^{7}$ Clinical Pharmacology \\ Unit, ACM Hospital Universitario y \\ Politécnico La Fe, Valencia, Spain
}

\begin{abstract}
The antitumor response after therapeutic vaccination has a limited effect and seems to be related to the presence of $\mathrm{T}$ regulatory cells (Treg), which express the immunoregulatory molecules CTLA4 and Foxp3. The blockage of CTLA4 using antibodies has shown an effective antitumor response conducing to the approval of the human anti-CTLA4 antibody ipilimumab by the US Food and Drug Administration. On the other hand, Foxp3 is crucial for Treg development. For this reason, it is an attractive target for cancer treatment. This study aims to evaluate whether combining therapeutic vaccination with CTLA4 or Foxp3 gene silencing enhances the antitumor response. First, the "in vitro" cell entrance and gene silencing efficacy of two tools, 2'-O-methyl phosphorotioate-modified oligonucleotides (2'-OMe-PS-ASOs) and polypurine reverse Hoogsteen hairpins (PPRHs), were evaluated in EL4 cells and cultured primary lymphocytes. Following B16 tumor transplant, C57BL6 mice were vaccinated with irradiated B16 tumor cells engineered to produce granulocyte-macrophage colony-stimulating factor (GM-CSF) and were intraperitoneally treated with CTLA4 and Foxp3 2'-OMe-PS-ASO before and after vaccination. Tumor growth, mice survival, and CTLA4 and Foxp3 expression in blood cells were measured. The following results were obtained: 1) only 2'-OMe-PS-ASO reached gene silencing efficacy "in vitro"; 2) an improved survival effect was achieved combining both therapeutic vaccine and Foxp3 antisense or CTLA4 antisense oligonucleotides (50\% and $20 \%$, respectively); 3 ) The blood $\mathrm{CD} 4{ }^{+} \mathrm{CD} 25^{+} \mathrm{Foxp}^{+}$(Treg) and $\mathrm{CD} 4{ }^{+} \mathrm{CTLA} 44^{+}$cell counts were higher in mice that developed tumor on the day of sacrifice. Our data showed that tumor cell vaccine combined with Foxp3 or CTLA4 gene silencing can increase the efficacy of therapeutic antitumor vaccination.
\end{abstract}

Keywords: gene silencing, antitumor vaccine, Treg, antisense oligonucleotide, cancer immunotherapy

\section{Introduction}

Cell vaccines genetically modified to produce proinflammatory cytokines have been shown to be effective in several types of cancer. ${ }^{1-10}$ One of the most successful vaccination approaches in experimental models involves the use of preventive granulocyte-macrophage colony-stimulating factor (GM-CSF)-engineered tumor cell vaccines, ${ }^{8-10}$ achieving 100\% survival among mice bearing B16 melanoma xenografts. However, in the therapeutic setting, such vaccines failed to improve overall survival, though they delayed tumor growth and prolonged animal lifetime. ${ }^{9-12}$ It is currently accepted that failure of the antitumor response in the therapeutic setting could be due to negative immunoregulatory action mediated by regulatory T cells (Treg), which express CTLA4 and Foxp3. CTLA4 is a coinhibitory molecule
Correspondence: María José Herrero Unidad de Farmacología Clínica, ACM Hospital Universitario y Politécnico La Fe, Fernando Abril Martorell I06, 46026 Valencia, Spain

Tel +34 96I 244985

Email maria.jose.herrero@uv.es
OncoTargets and Therapy 2017:10 503-5/4

503

Dovepress f $y$ in $\mathbf{0}$

http://dx.doi.org/10.21 47//OTT.S104393. (c) (1) (5) 2017 Miguel et al. This work is published and licensed by Dove Medical Press Limited. The full terms of this license are available at https://www.dovepress.com/terms.php
and incorporate the Creative Commons Attribution - Non Commercial (unported, v3.0) License (http://creativecommons.org/licenses/by-nc/3.0/). By accessing the work you (c)
hereby accept the Terms. Non-commercial uses of the work are permitted without any further permission from Dove Medical Press Limited, provided the work is properly attributed. For permission for commercial use of this work, please see paragraphs 4.2 and 5 of our Terms (https://www.dovepress.com/terms.php). 
that binds B7 molecules with more affinity than CD28 coactivator. The interaction of CTLA4 with B7 molecule induces downregulatory signals, ${ }^{13,14}$ and accordingly, antiCTLA4 antibodies have been shown to induce effective antitumor responses in clinical trials, ${ }^{15,16}$ leading to their approval by the US Food and Drug Administration (FDA) for treating advanced melanoma. Since antibodies can only block surface molecules and have very limited intracellular access, the use of gene silencing strategies to block the expression of intracellular molecules such as nuclear transcription factor Foxp3 could be an interesting treatment approach, since Foxp3 plays an important role in Treg cell (CD4+CD25+Foxp3+) development and function. ${ }^{17,18}$ Recently, a study in a model of murine melanoma has shown that gene silencing of Foxp3 in B16 tumor cells, using an siRNA plasmid, delays tumor growth and modifies the tumor immunosuppressive environment. ${ }^{19}$

The aim of the present study was to evaluate the possible synergistic antitumor effect using Foxp3 or CTLA4 gene silencing treatment before therapeutic vaccination, employing GM-CSF-engineered tumor cells. For gene silencing, we used two nuclease resistant oligonucleotides: 2'-O-methylphosphorotioate-modified oligonucleotides (2'-OMe-PS-ASOs) and polypurine reverse Hoogsteen hairpins (PPRHs), which are DNA hairpins formed by two antiparallel polypurine chains joined by reverse Hoogsteen bonds. Although both antisense oligonucleotides (ASOs) and PPRHs have yielded promising results in preclinical studies, ${ }^{20-23}$ only ASOs have demonstrated clinical interest. Our "in vitro" studies indicate that only ASOs could be used for "in vivo" experiments, since naked PPRHs showed low cell entrance and gene silencing efficacy. Using the best ASO found in our "in vitro" studies, we conducted "in vivo" experiments that revealed a synergistic antitumor effect (50\% mice survival) employing Foxp3 ASO plus GM-CSF cell vaccine, thus suggesting the potential interest of gene silencing strategies in cancer treatment.

\section{Materials and methods}

\section{Nucleic acids}

The plasmid employed was p2F GM-CSF (Figure 1) derived from the pVITRO2 base plasmid (InvivoGen, San Diego,
CA, USA), which carries the murine gm-csf gene under the control of the ferritin promoter.

To design the PPRHs, we used the Triplex-Forming Oligonucleotide Target Sequence Search tool from the MD Anderson Cancer Center (Houston, TX, USA) website. The ASOs were directed against the same target sequences as the PPRHs, and were used with the 2'-O-methyl phosphorotioate modification (2'-OMe-PS-ASO). ASOs and PPRHs were purified by high-performance liquid chromatography. PPRHs were purchased from Thermo Fisher Scientific (Waltham, MA, USA) and 2'-OMe-PS-ASOs were purchased from biomers. net $\mathrm{GmbH}$ (Ulm, Germany). The sequences corresponding to the designed ASOs and PPRHs are given in Table 1. The designed ASO and PPRH controls correspond to oligonucleotides with average sizes equivalent to those of ASO and PPRH used in this study and with scrambled sequence.

\section{Animals and cells}

Male C57BL/6 mice (8-10 weeks old) were kept under standard laboratory conditions. The maximum number of mice housed per cage was ten. All the mice used in this work were labeled in the ears for identification purposes. The experimental project (A1319118959093) was approved by the Biological Research Committee of the University of Valencia (Valencia, Spain) and followed European directive 63/2010 and Spanish directive RD 53/2013 for animal care. B16 murine melanoma cells were used for the vaccination experiment in syngeneic C57BL/6 mice. Tumor cells were transfected using p2F GM-CSF/PEI 25 kDa (polyethyleneimine; Sigma-Aldrich Co., St Louis, MO, USA) polyplexes (DNA:PEI, 1:1.41 w/w) with $20 \mu \mathrm{g} / \mathrm{mL}$ of plasmids, as previously described, ${ }^{24,25}$ and were irradiated after 24 hours with $150 \mathrm{~Gy}$. Then, cells were frozen and stored at $-80^{\circ} \mathrm{C}$ until further use. Murine lymphoblastic lymphoma EL4.BU.OU6 cells and mouse lymphocytes in primary culture were also used for "in vitro" gene silencing experiments. EL4 cells were used because they express the target genes. Murine melanoma B16 cells and thymoma murine EL4.BU.OU6 cell line were purchased from European Collection of Cell Cultures (Salisbury, UK), and lymphocytes were obtained from mouse blood ( $50 \mu \mathrm{L} /$ mouse) by saphen vein puncture through gradient centrifugation using Ficoll-Paque Plus ${ }^{\circledR}$ (GE Healthcare Bio-Sciences Corp., Piscataway, NJ, USA).

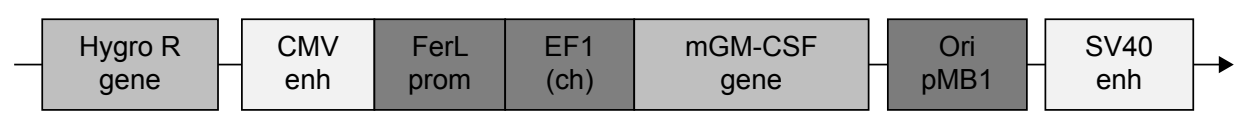

Figure I p2F GM-CSF plasmid schema.

Abbreviations: Hygro R gene, hygromycin resistance gene; CMV enh, cytomegalovirus enhancer; FerL prom, light chain ferritin promoter; EFI, elongation factor-I; mGM-CSF, mouse granulocyte-macrophage colony-stimulating factor gene; Ori pMBI, replication origin from plasmid pMBI; SV40 enh, simian vacuolating virus 40 enhancer. 
Table I Sequence and location of all 2'-OMe-PS-ASOs and PPRHs tested

\begin{tabular}{|c|c|c|}
\hline Name & Location (target) & Sequence $\left(5^{\prime} \rightarrow 3^{\prime}\right)$ \\
\hline \multicolumn{3}{|l|}{ CTLA4 } \\
\hline ASO I & Intron 3 (coding) & GGAGGAGTAGGAAGAGTAAG \\
\hline ASO 2 & Exon I (coding) & GAAGAGTGAGCAGGG \\
\hline ASO 9 & Intron 3 (template) & GAATGAGAAGGATGAGGAGG \\
\hline ASO 10 & Exon I (template) & GGGACGAGTGAGAAG \\
\hline PPRH I & Intron 3 (coding) & GAAAGAGAAGGAAGAGGAGGTTTTTGGAGGAGAAGGAAGAGAAAG \\
\hline PPRH 2 & Exon I (coding) & GGGAAGAGAGAGAAGTTTTTGAAGAGAGAGAAGGG \\
\hline PPRH 5 & Intron 3 (template) & GGGAAAGGAAGGAAGAGGAATTTTTAAGGAGAAGGAAGGAAAGGG \\
\hline PPRH 6 & Exon I (template) & AGAGGAGAGAGGAAGTTTTTGAAGGAGAGAGGAGA \\
\hline \multicolumn{3}{|r|}{ 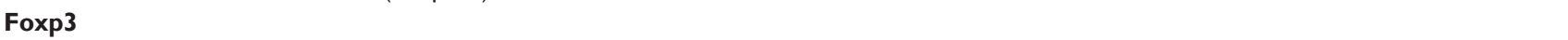 } \\
\hline ASO 3 & Exon I3 (coding) & AGGAGATAGAGTGGAGGGG \\
\hline ASO 4 & Intron I (coding) & GGGGGAAGCACGGAAGGG \\
\hline ASO II & Exon I3 (template) & GGGGAGGTGAGATAGAGGA \\
\hline ASO 12 & Intron I (template) & GGGAAGGCACGAAGGGGG \\
\hline PPRH 3 & Exon 13 (coding) & GGGGAGGAGAGAAAGAGGATTTTTAGGAGAAAGAGAGGAGGGG \\
\hline PPRH 4 & Intron I (coding) & GGGAAGGAAAGAAGGGGGTTTTTGGGGGAAGAAAGGAAGGG \\
\hline PPRH 8 & Exon 13 (template) & GAGGGAAGAGAGAGAGGAGAGTTTTTGAGAGGAGAGAGAGAAGGGAG \\
\hline PPRH 9 & Intron I (template) & AAGAGGGGAAGAAGGGGTTTTTGGGGAAGAAGGGGAGAA \\
\hline \multicolumn{3}{|r|}{ 皮 } \\
\hline ASOcont & Scrambled & AGGAGGACAGGAGAGTAGA \\
\hline PPRHcont & Scrambled & AGGAGGAAAGGAGAGAAGATTTTTAGAAGAGAGGAAAGGAGGA \\
\hline
\end{tabular}

Abbreviations: ASO, antisense oligonucleotide; PPRH, polypurine reverse Hoogsteen hairpin; cont, control; ASOcont, ASO scrambled sequence; PPRHcont, PPRH scrambled sequence.

\section{In vitro experiments}

EL4 cells and primary cultured mouse lymphocytes $\left(1 \times 10^{6}\right.$ cells $)$ were incubated in the presence of different concentrations of 2'-OMe-PS-ASO-control and PPRH-control labeled with FAM at different time points. Then the cells were analyzed by flow cytometry (FACS Verse [BD Biosciences, San Jose, CA, USA] and AMNIS ImageStreamX Mark II [EMD Millipore, Billerica, MA, USA] to determine whether 2'-OMe-PS-ASO-FAM and PPRH-FAM) entered the cell or remained attached to the membrane. The naked ASO-control and PPRH-control were added to culture medium without any carrier. They probably enter into the cell through a concentration-dependent mechanism, since energy-dependent transport has not been reported to the best of our knowledge.

EL4 and lymphocytes were incubated in the presence of 2'-OMe-PS-ASO and PPRH for different time points (1-48 hours) and concentrations ( $1 \mathrm{nM}-1 \mathrm{mM})$. Then, RNA was extracted and the mRNA levels of CTLA4 and Foxp3 were evaluated by quantitative reverse transcription polymerase chain reaction (RT-PCR). Since mRNA expression in untreated cells and in cells treated with PPRH-control and ASO-control was the same, these were considered as reference value $(100 \%)$ to calculate the silencing efficiency of the specific ASO and PPRH, respectively.Cellular toxicity of oligonucleotides was evaluated using the calcein-AM test (Thermo Fisher Scientific).

\section{Plasma concentrations of 2'-OMe-PS- ASO and PPRH in mice}

2'-OMe-PS-ASO (87 $\mu \mathrm{g} /$ mouse) and PPRH (175 $\mu \mathrm{g} / \mathrm{mouse})$ labeled with FAM were injected intraperitoneally into C57BL/6 mice $(n=3)$, and their plasma concentrations at different time points were evaluated. Blood samples $(50 \mu \mathrm{L}$ from saphenous vein) were obtained 5, 15, and 30 minutes, and 1, 2, 4, 6, 12, 24, and 48 hours after injection. Fluorescence in blood was measured with a fluorimeter (CytoFluor 2350; EMD Millipore), and their concentrations were determined from the equation of the curve.

\section{Therapeutic vaccines plus gene silencing}

B16 cells genetically modified and irradiated as explained in "Animals and cells" section were thawed, washed, counted in a Bauer chamber, and resuspended $\left(2 \times 10^{6}\right.$ cells/mouse $)$ in $200 \mu \mathrm{L}$ Dulbecco's Modified Eagle's Medium (DMEM), and were subcutaneously (in the back) injected on days 3 , 10 , and 17 after tumor subcutaneous injection (day $0,2 \times 10^{4}$ wild-type nonirradiated B16 cells) in the left leg. In addition, 2'-OMe-PS-ASO-control, 2'-OMe-PS-ASO anti-CTLA4, and/or 2'-OMe-PS-ASO anti-Foxp3 were injected on days $2,4,7$, and 9 . The blood samples $(50 \mu \mathrm{L})$ were taken on days $-7,2,4,8,11,15,18$, and 21 by puncture of saphen vein (maximum $200 \mu \mathrm{L} /$ mouse every 21 days). CTLA4 and Foxp3 mRNA expression of genes in peripheral blood lymphocytes was studied. 
The vaccination groups were as follows: a) control, DMEM only; b) Vac+ASOcont, transfected irradiated B16 cells vaccine and 2'-OMe-PS-ASO-control administered; c) Vac+ASOctla4, transfected irradiated B16 cells vaccine and 2'-OMe-PS-ASO anti-CTLA4 administered; and d) Vac+ASOfoxp3, transfected irradiated B16 cells vaccine and 2'-OMe-PS-ASO anti-Foxp3 $(n=19, n=5$ per group, except group "d", where $n=4$, due to failure in the first 2'-OMe-PS-ASO administration). Mice were assigned to groups on a random basis.

To determine the presence of depigmentation or diarrhea as possible adverse effects, animals were visually monitored and weighed three times a week. Tumor growth in mice was also visually monitored and measured with a caliper in two dimensions: $\mathrm{A}$ (long diameter) and $\mathrm{B}$ (short diameter). Tumor volume was calculated with the formula: $\mathrm{V}=(\mathrm{A} \times \mathrm{B} 2) / 2$. When tumor volume reached $1,500 \mathrm{~mm}^{3}$, animals were euthanized, and "date of death" was recorded to construct survival curves. Lungs were extracted to study the possible presence of metastases. Furthermore, blood was extracted through the cava vein to conduct a study of Treg and CTLA4 lymphocytes in blood. Mice were anesthetized with isoflurane (IsoFlo; Esteve, Barcelona, Spain) before euthanasia and before tumor vaccine and tumor injection.

\section{Characterization of Treg and CD4 ${ }^{+}$CTLA4 ${ }^{+}$cells by flow cytometry}

Lymphocytes were separated from blood using Ficoll-Paque Plus (GE Healthcare Bio-Sciences Corp.). The lymphocyte sample of each group was divided into two parts: one for $\mathrm{CD} 4^{+} \mathrm{CTLA} 4^{+}$staining and the other for dyeing Treg $\left(\mathrm{CD} 4{ }^{+} \mathrm{CD} 25^{+} \mathrm{Foxp} 3\right)$ lymphocytes. To determine CD4+ lymphocytes, we used goat fluorescein isothiocyanate (FITC)-labeled anti-mouse CD4, and to determine CTLA4 lymphocytes, we used goat phycoerythrin (PE)-labeled antimouse CTLA4 - both from eBioscience (Santa Clara, CA, USA). To determine the number of Treg lymphocytes, we used Mouse Regulatory T Cell Staining Kit \# 2 (eBioscience). The samples were analyzed by flow cytometry (FACS Verse; BD Biosciences).

\section{Quantitative RT-PCR}

To quantify the mRNA of CTLA4 and Foxp3, RNA from cultured cells or peripheral blood was obtained with a commercial kit (RNeasy Mini Kit [Quiagen NV, Venlo, the Netherlands] or NuceloSpin ${ }^{\circledR}$ Blood RNA [Machery-Nagel Inc., Dueren Germany], respectively). RNA was converted into cDNA by retrotranscription. RT and quantitative PCR allowed quantification of the number of copies of mRNA using a 7900HT Fast Real-Time PCR System (Thermo Fisher Scientific). The number of mRNA copies was obtained from dose-response curves of Ct versus DNA copy number. To amplify DNA of CTLA4 and Foxp3, TaqMan Copy Number Assays (Thermo Fisher Scientific) were used.

\section{Statistical methods}

Data were summarized as the mean and standard deviation in the case of continuous variables and as relative and absolute frequencies in the case of categorical variables. Multiple linear regression was used for assessing differences in tumor growth among groups and for comparing mRNA expression levels. Final survival differences between groups were assessed using L2-penalized logistic regression (ridge logistic regression), and survival curves were compared with a Cox regression model. Lymphocyte populations were compared using a beta-regression model. All statistical analyses were performed using R software 3.2.1.

\section{Results 2'-OMe-PS-ASO penetrates cells better than PPRH}

Mouse peripheral blood lymphocytes and EL4 cells were incubated with PPRH-FAM or 2'-OMe-PS-ASO-FAM for 24 hours, and the percentage of labeled cells was analyzed by flow cytometry (Figure 2A and B). A higher concentration of PPRH than of 2'-OMe-PS-ASO was needed to achieve the same percentage of labeled EL4 cells and lymphocytes (200-fold and tenfold, respectively). Likewise, 100-fold and fivefold higher concentrations of 2'-OMe-PS-ASO and PPRH in lymphocytes versus EL4 cells, respectively, were required to achieve the same percentage of labeled cells.

Figure $2 \mathrm{C}$ provides a representative image of EL4 cells labeled with 2'-OMe-PS-ASO-FAM and PPRH-FAM (green fluorescence), showing that the molecules are located within the cell and are not absorbed in the surface membrane. The AMNIS algorithm for calculating the percentage of internalization of 2'-OMe-PS-ASO-FAM and PPRH-FAM indicated a penetration of $95 \%-99 \%$. We thus confirmed that 2 -OMePS-ASO and PPRH were effectively entering the cells.

\section{In vitro gene silencing with 2'-OMe-PS- ASO is more effective than PPRH}

The "in vitro" gene silencing efficacy of the designed PPRH and 2'-OMe-PS-ASO was evaluated in EL4 cells. We used cells incubated in the absence of $2^{\prime}$-OMe-PS-ASO or PPRH as controls. The groups treated with ASO-control and 
A

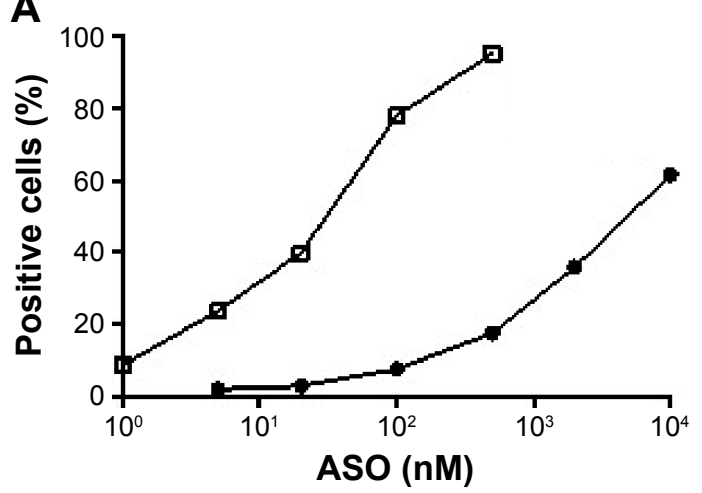

B

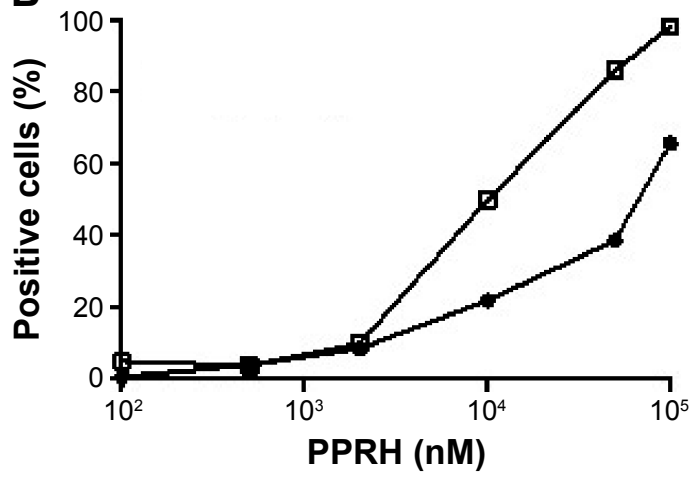

C ๑ EL4 - Lymphocytes

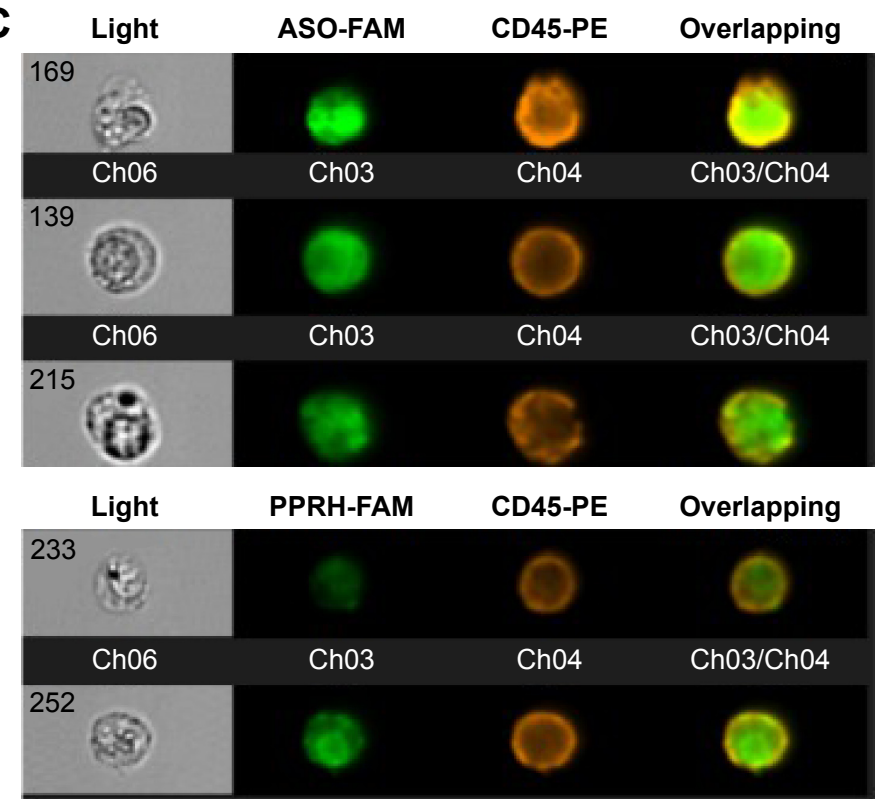

Figure 2 Identification of EL4 ASO-FAM- and PPRH-FAM-positive lymphocytes and EL4 cells.

Notes: EL4 cells or mouse lymphocytes extracted from peripheral blood were incubated in the presence of different concentrations of ASO-FAM (A) and PPRH-FAM (B) during 24 hours and were then analyzed by flow cytometry. The percentages of ASO-FAM-positive and PPRH-FAM-positive cells are represented in the figures. (C) Intracellular presence of ASO and PPRH in EL4 cells is shown. Image was taken with the AMNIS flow cytometer, where it can be observed that ASO-FAM and PPRH-FAM (green) are located within the cell. EL4 cells were incubated with ASO-FAM and PPRH-FAM (green) and anti-CD45 (orange).

Abbreviations: ASO, antisense oligonucleotide; PPRH, polypurine reverse Hoogsteen hairpin; FAM, 6-Carboxyfluorescein; PE, phycoerythrin.

PPRH-control obtained the same level of mRNA expression of target genes as the nontreated cells; we considered this mRNA expression to represent $100 \%$ expression in order to establish comparisons with the other groups. The results of gene expression inhibition are represented in Figure 3A-D. 2 -OMe-PS-ASO achieved the best results at a concentration of $1 \mu \mathrm{M}$, determining the levels of mRNA 48 hours posttransfection. The best results were achieved with 2 '-OMe-PSASO 2 and 2'-OMe-PS-ASO 4, inhibiting mRNA expression of CTLA 4 and Foxp 3 by up to $52 \%$ and $50 \%$, respectively. In contrast, the "in vitro" efficacy of PPRH was always lower than $13 \%$. The data showed that higher concentrations of PPRH than of 2'-OMe-PS-ASO were necessary to silence a gene. Cell viability in all cases was greater than $70 \%$
(Figure 3E and F), indicating that neither ASO nor PPRH induced relevant cytotoxicity "in vitro" 48 hours after they were added to the cells.

\section{Plasmatic concentrations of 2'-OMe-PS- ASO and PPRH}

The results of the study of the plasmatic concentrations of 2'-OMe-PS-ASO and PPRH after peritoneal injection in mice are shown in Figure 4. A first absorption step of 2 '-OMe-PS-ASO was observed in which the maximum concentration was reached in blood within 30 minutes, and from this moment onward a sharp drop in blood concentration was recorded (rapid kinetic disposition), followed by a slower fall (slow kinetic disposition) - becoming negligible 

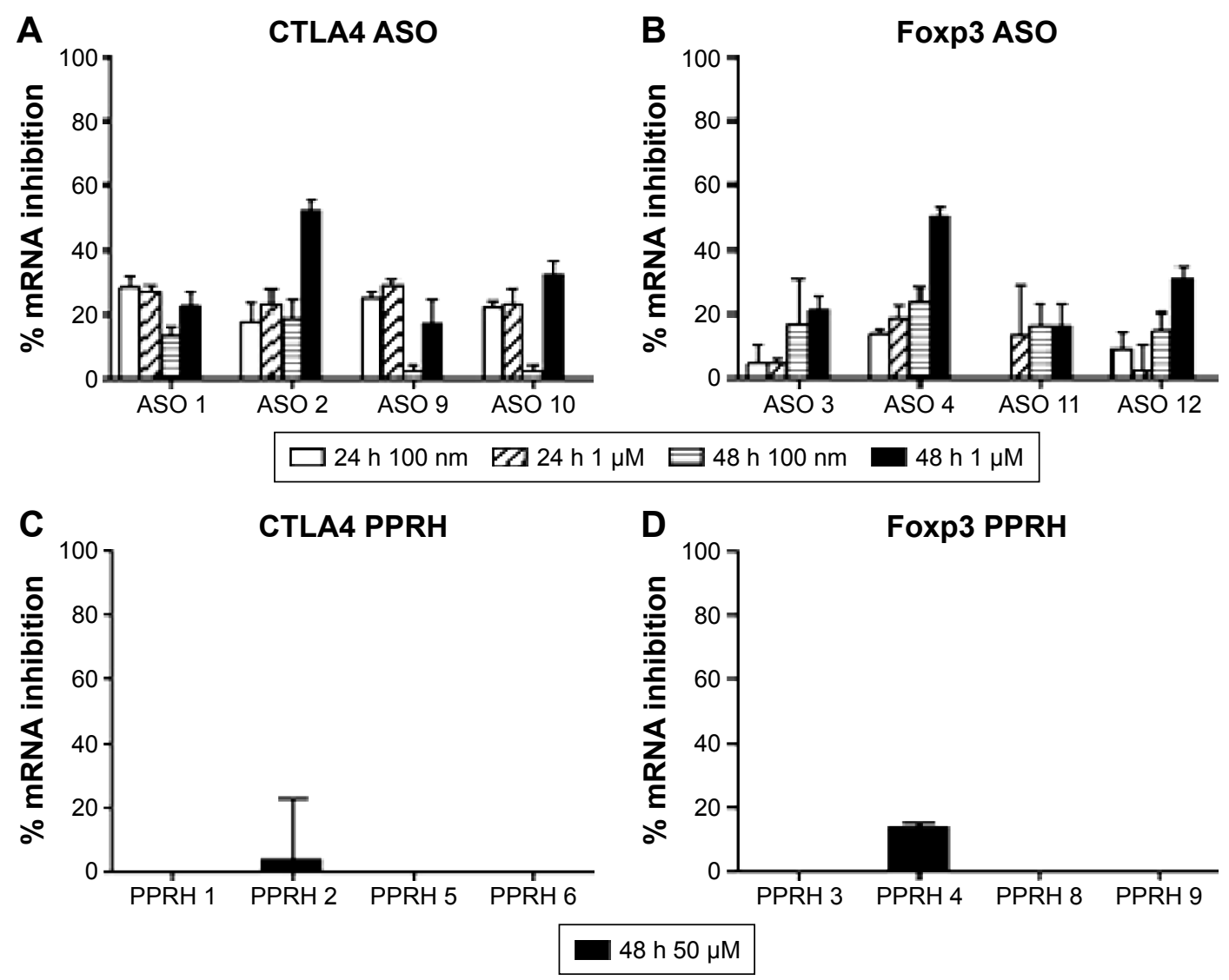

E CTLA4

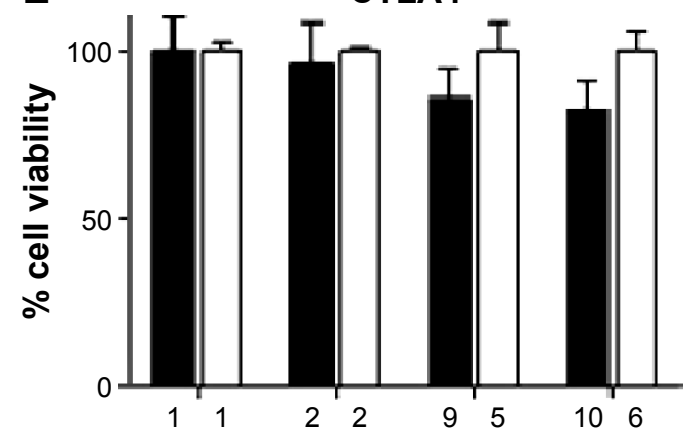

$\mathbf{F}$

Foxp3

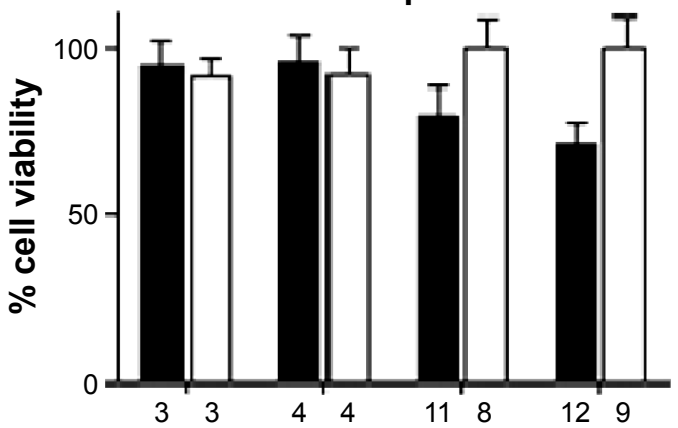

ASO $1 \mu \mathrm{M} \square$ PPRH $50 \mu \mathrm{M}$

Figure 3 In vitro effect of ASO and PPRH in CTLA4 and Foxp3 expression and cytotoxicity.

Notes: (A-D) CTLA4 and Foxp3 in vitro gene silencing is shown. EL4 cells were incubated in the presence of different concentrations of ASO or PPRH versus CLA4 and Foxp3 genes for I hour, and RNA extraction was performed at 24 hours or 48 hours. The figures show the percentage inhibition of mRNA of each gene versus control (no ASO or PPRH) ( $n=2)$. (E, F) Cytotoxicity of ASO and PPRH is shown. EL4 cells were incubated for 24 hours or 48 hours in the presence of anti-CTLA4 ASO or antiFoxp3 ASO $(\mathrm{I} \mu \mathrm{M})$, or for 48 hours in the presence of PPRH $(50 \mu \mathrm{M})$. Calcein-AM was added, and cell viability was determined by testing calcein ester metabolism. Figures represent the percentage viability of cells incubated with ASO and PPRH $(n=2)$.

Abbreviations: ASO, antisense oligonucleotide; PPRH, polypurine reverse Hoogsteen hairpin.

at 4 hours after injection. We observed similar results with PPRH, though the fall in concentration in the rapid disposition phase was more pronounced - reaching low blood concentrations sooner. With these data, we calculated that the amounts of $2^{\prime}$-OMe-PS-ASO and PPRH that would be required to achieve potential therapeutic concentrations in blood, according to the "in vitro" silencing studies, would be $500 \mu \mathrm{g}$ per mouse and $19.5 \mathrm{mg}$ per mouse, respectively.
Due to the high amounts required for PPRH (without vector), they were not included in the "in vivo" experiments.

\section{Tumor cell vaccine plus CTLA4/Foxp3 gene silencing delays tumor growth}

Based on aforementioned results, we examined whether the combination of therapeutic cell vaccine with gm-csf genetically modified cells and CTLA4/Foxp3 gene silencing 

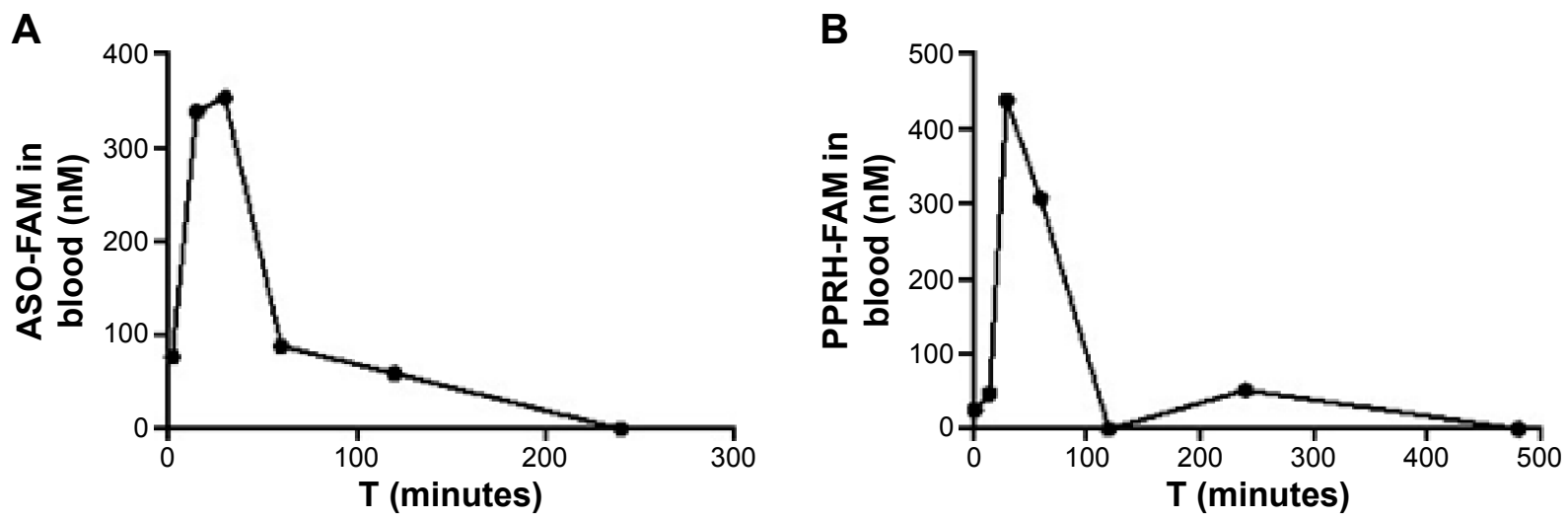

Figure 4 Plasma concentrations of ASO and PPRH.

Notes: Scrambled ASO ( $87 \mu \mathrm{g} /$ mouse) or PPRH (I75 $\mu \mathrm{g} /$ mouse) marked with the fluorochrome FAM was administered intraperitoneally to C57BL/6 mice, and blood samples were taken at different time points $(5,15,30,60,120,240$, and 480 minutes). Fluorescence of each blood sample was measured, and ASO-FAM and PPRH-FAM concentrations were determined from a standard curve. Figures represent the kinetics of ASO $(\mathbf{A})$ and PPRH $(\mathbf{B})$ after intraperitoneal administration $(\mathrm{n}=2)$.

Abbreviations: ASO, antisense oligonucleotide; PPRH, olypurine reverse Hoogsteen hairpin; FAM, 6-Carboxyfluorescein.

promoted tumor rejection in mice. We selected 2 '-OMe-PSASO 2 and 2'-OMe-PS-ASO 4 to silence CTLA4 gene and Foxp3 gene, respectively. The results of tumor volumes obtained this experiment are shown in Figure 5A-D. Only mice that developed tumor are represented in these figures; the rest of mice did not develop tumor. The tumor began to be visible from day 15 onward. Tumor growth was slower in mice of the Vac+ASOctla4 and Vac+ASOfoxp3 groups. Mice belonging to the Vac+ASOfoxp3 group showed delayed tumor growth more than any other group but no significant differences were observed between the groups.

\section{Tumor cell vaccine plus CTLA4/Foxp3 gene silencing improves survival in mice}

The survival curves of the different treated groups are represented in Figure 5E. Vac+ASOfoxp3 was the the best performing group, achieving 50\% (2/4) survival $(P=0.04)$. Both the Vac+ASOctla4 and Vac+ASOcont groups achieved $20 \%(1 / 5)$ overall survival.

There were no cases of lung metastases that were detected, and no cases of animal depigmentation or diarrhea were observed.

\section{Early CTLA4 and Foxp3 mRNA expression is related to tumor development}

CTLA4 and Foxp3 gene expression was studied in the vaccinated mice. With the aim of obtaining enough blood to guarantee effective mRNA extraction, all blood samples were pooled in only two different groups according to the success of the response against the tumor: "nonresponders" (tumor development, $\mathrm{n}=15$ ) or "responders" (no tumor development, $n=4)$. Blood samples from days -7 and 2 (before any treatment) were pooled for this experiment, as they were expected to yield homogeneous results, since they all belonged to syngeneic mice without any pretreatment. Figure $6 \mathrm{~A}$ and $\mathrm{B}$ represents the mRNA copy number of these genes transcribed in the nonvaccinated control group (only tumor was implanted).

Figure 6A shows a peak of CTLA4 mRNA expression on day 4 (12,000 mRNA copies of CTLA4/100 ng total RNA) and another lower peak on day 11. On the remaining days, mRNA production was more similar to day -7 (2,000 CTLA4 mRNA copies/100 ng total RNA). Figure 6B shows a peak of Foxp3 mRNA expression on days 2 and 4 (1,900 Foxp3 mRNA copies/100 ng total RNA) and another lower peak on day 11 . On the remaining days, Foxp 3 mRNA expression was more similar to day -7 (700 Foxp3 mRNA copies/100 ng total RNA).

Figure $6 \mathrm{C}$ and $\mathrm{D}$ represents the difference in percentage of CTLA4 and Foxp3 mRNA copies with respect to day -7 in the responder versus the nonresponder group. CTLA4 and Foxp3 mRNA expression was lower in the responder group than in the nonresponder group on day 4 and higher on day 11 ( $P=0.0032$ in CTLA4 and $P=0.0088$ in Foxp 3 ).

\section{Blood CD4 ${ }^{+} \mathrm{CTLA}^{+}$and} CD4 ${ }^{+} \mathrm{CD} 25^{+} \mathrm{Foxp}^{+}$cells are more

\section{numerous in nonresponders than in responders}

With the aim of determining whether there were differences between the nonresponder and responder groups in the Treg $\left(\mathrm{CD} 4^{+} \mathrm{CD} 25^{+} \mathrm{Foxp}^{+}\right)$and $\mathrm{CD} 4^{+} \mathrm{CTLA} 4^{+}$lymphocyte populations, blood samples from mice included in the study and a new group of mice without tumor implantation $(n=5)$ were 
A
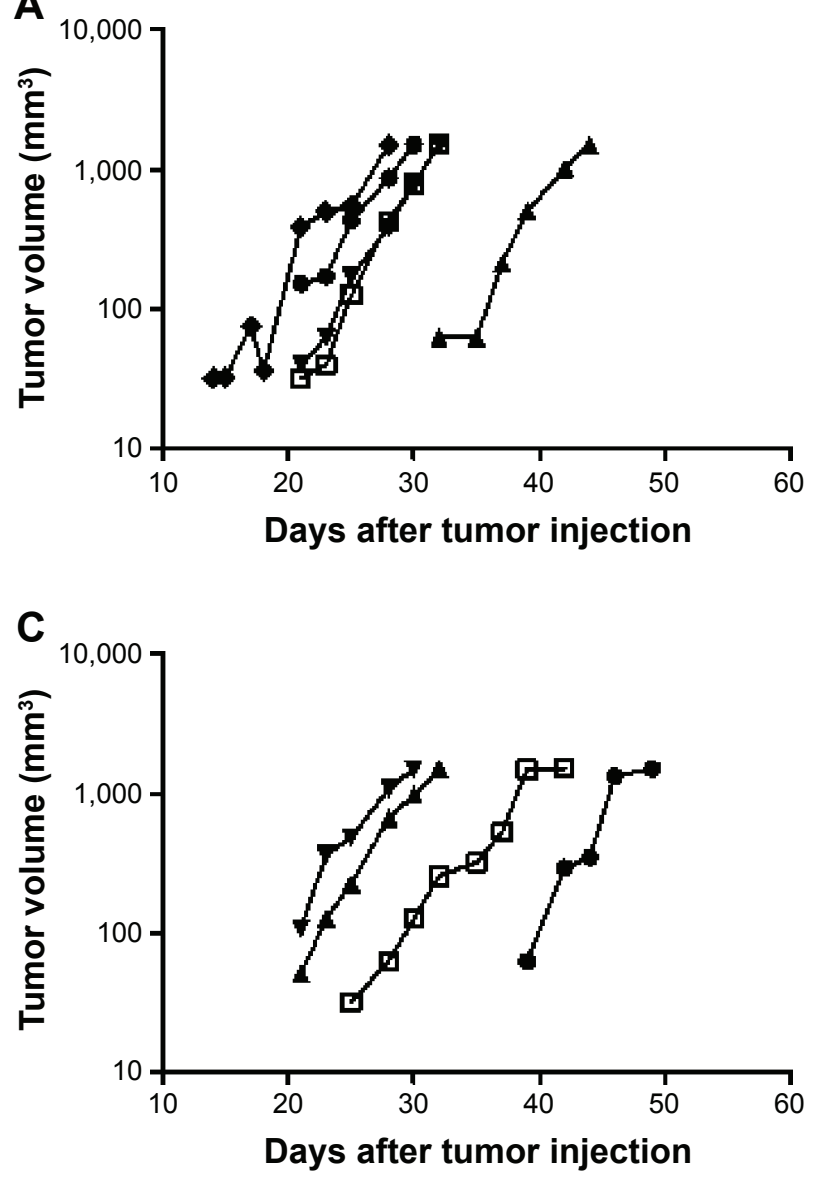

B

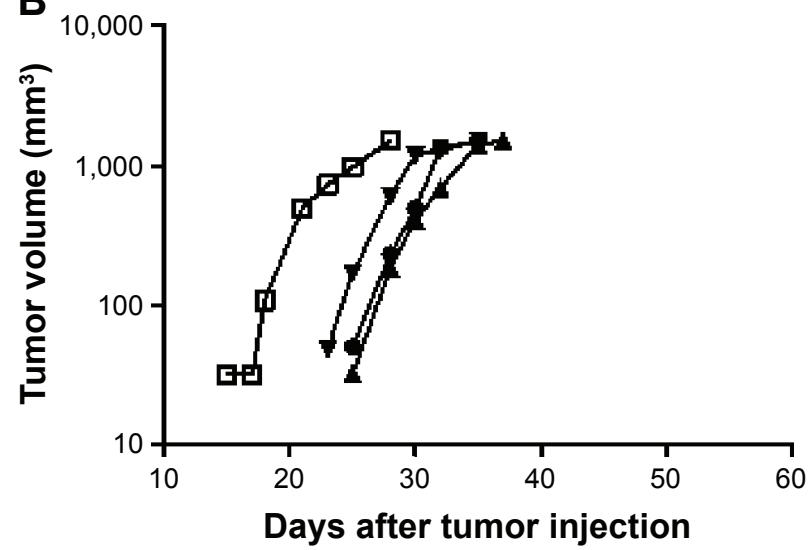

D

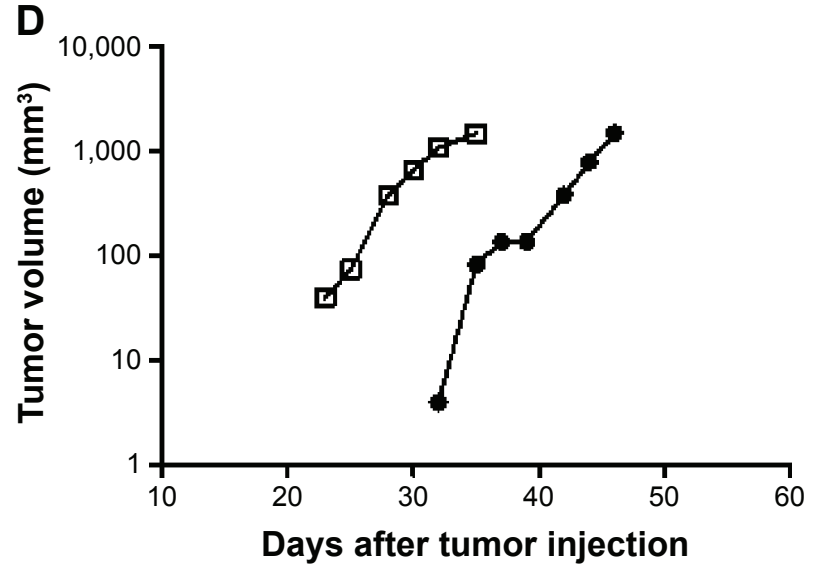

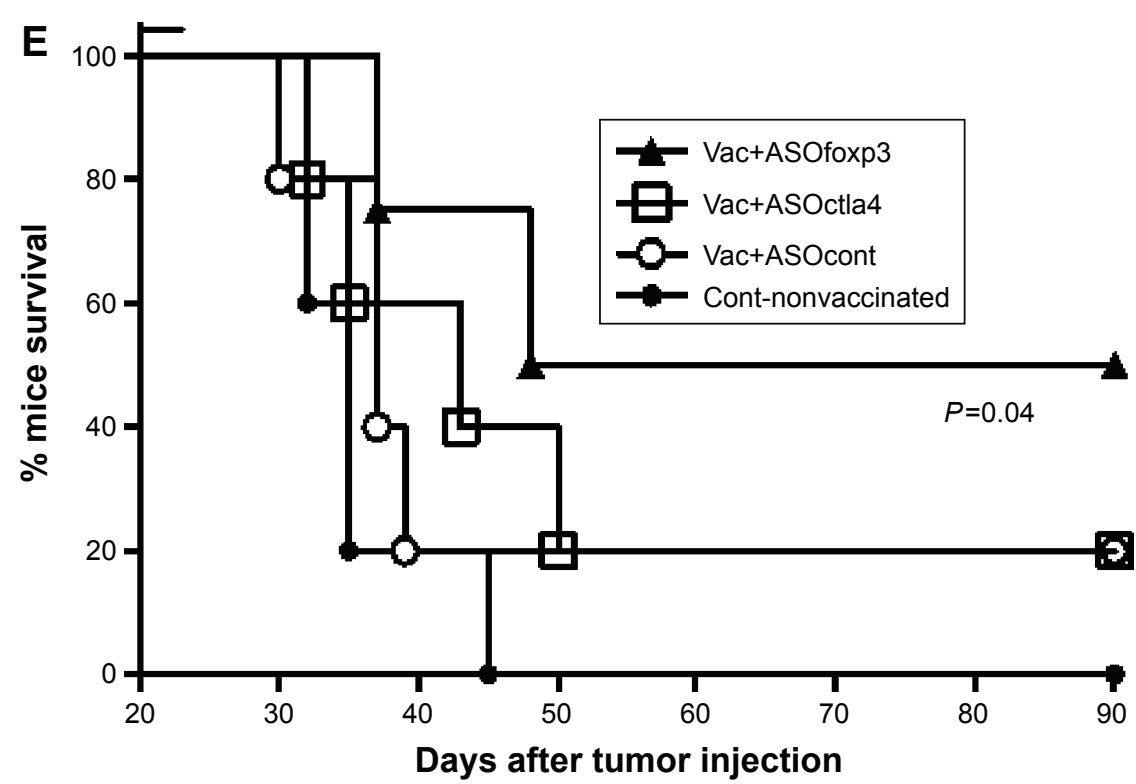

Figure 5 Tumor volume in mice vaccinated with transfected cells + ASO.

Notes: The figure represents the tumor volume of mice immunized with tumor irradiated and transfected cells on days 3 , 10, and I7 after tumor implantation (day 0 ) and administered ASO on days 2, 4, 7, and 9. Vaccination groups are represented in figures $\mathbf{A}-\mathbf{D}$, and animals that did not develop the tumor are not represented (total $\mathrm{n}=5$ per group, except group "D", where $n=4$ ). Different symbols allow differentiation of each mouse from the rest of its group. (A) Control-nonvaccinated, mice only injected with $100 \mu \mathrm{L}$ of DMEM; (B) Vac+ASOcont, mice vaccinated with irradiated BI6 cells producing GM-CSF and administered ASO-control; (C) Vac+ASOctla4, mice vaccinated with irradiated BI6 cells producing GM-CSF and administered anti-CTLA4 ASO; (D) Vac+ASOfoxp3, mice vaccinated with irradiated BI6 cells producing GM-CSF and administered anti-Foxp3 ASO. Logarithms of tumor volume were compared, and linear regression was used to calculate statistically significant differences, but were not found; (E) survival of treated mice. The figure shows the survival curves of the groups of animals from therapeutic vaccination + gene silencing described earlier. Logistic regression with ridge correction was used. Statistically significant difference versus control-nonvaccinated, $P=0.04$.

Abbreviations: ASO, antisense oligonucleotide; DMEM, Dulbecco's Modified Eagle's Medium; GM-CSF, granulocyte-macrophage colony-stimulating factor; Cont, control. 


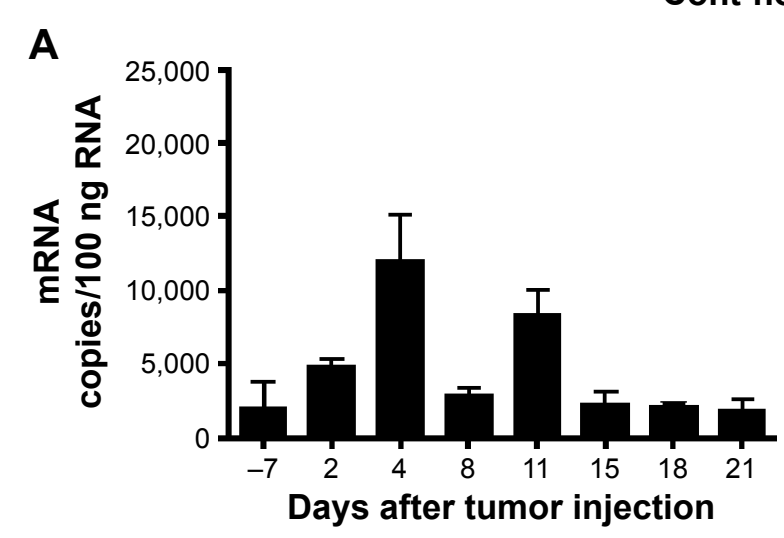

\section{Cont-non vaccinated mice}
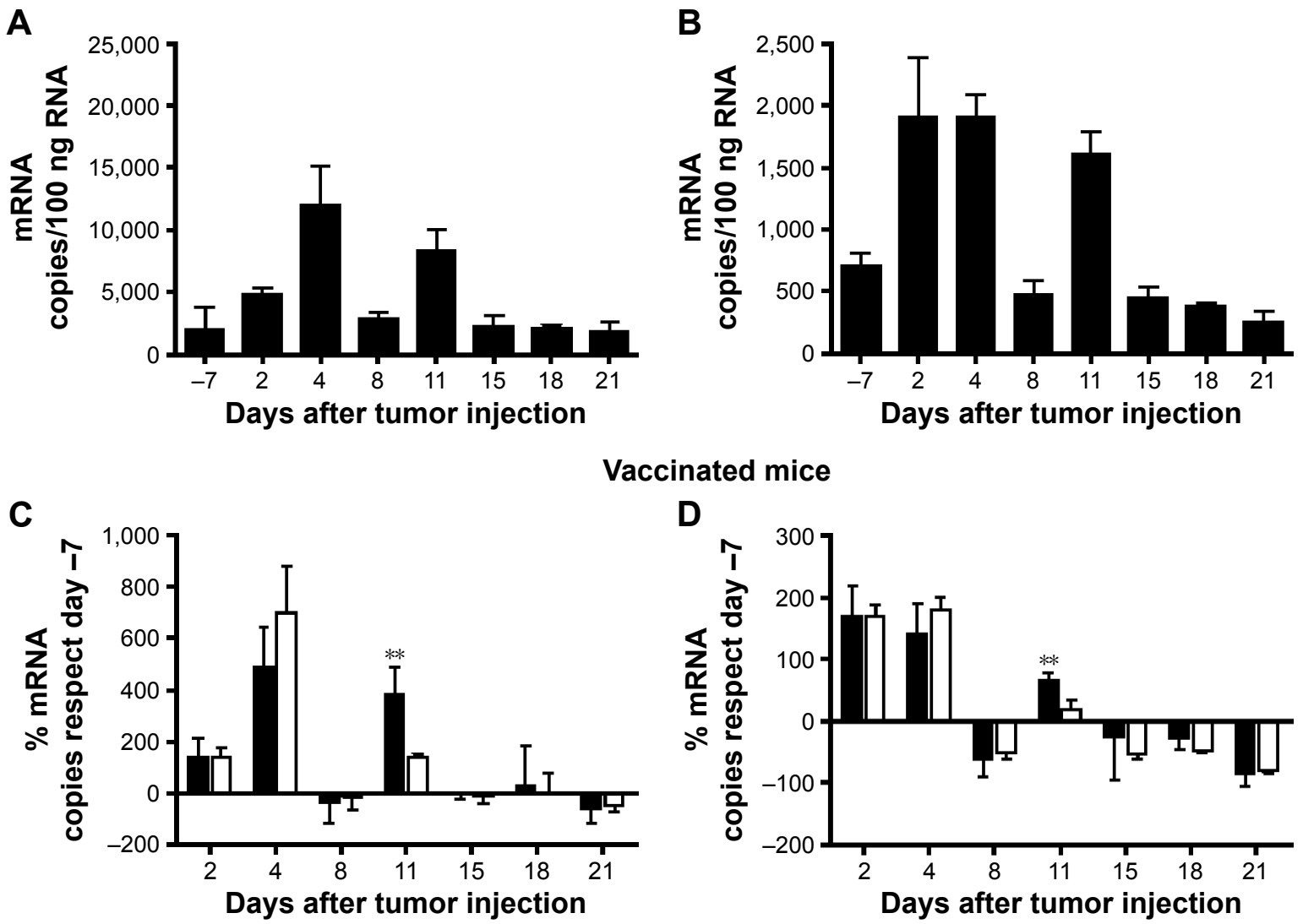

Vaccinated mice

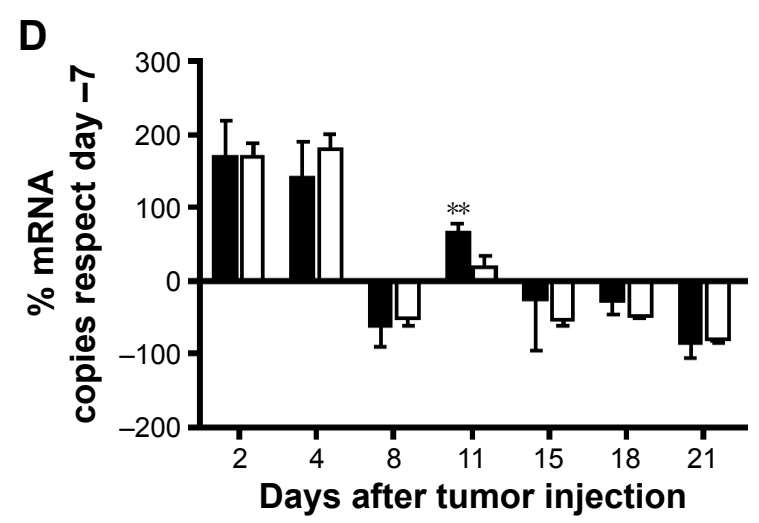

Responders

Non-responders

Figure 6 CTLA4 and Foxp3 expression after tumor implanted.

Notes: (A, B) CTLA4 and Foxp3 expression after tumor implanted in nonvaccinated mice. Figures represent mRNA copy number of CTLA4 (A) and Foxp3 (B)/ I00 ng total RNA on different days after tumor implantation (day 0 ) in the nonvaccinated control group. Animals of this group were administered DMEM after tumor injection ( $\mathrm{n}=5$ ). (C, D) CTLA4 and Foxp3 mRNA expression in the responder and nonresponder groups. The figure represents the difference in percentage mRNA copies of CTLA4 (C) and Foxp3 (D) with respect to day -7 in the responder $(n=4)$ and nonresponder $(n=15)$ groups. The bars of day 2 in both groups represent the same group, because on this day the blood from all mice was pooled. Statistically significant differences of each group versus the nonresponder group were calculated using a lineal model with different variance structures for each group, ${ }^{* *} P<0.01$

Abbreviations: DMEM, Dulbecco's Modified Eagle's Medium; Cont, control.

analyzed by flow cytometry. The results are represented in Figure 7. The responder group had a lower percentage of $\mathrm{CD}^{+}{ }^{+} \mathrm{CTLA} 4^{+}$and $\mathrm{CD} 4^{+} \mathrm{CD} 25^{+} \mathrm{Foxp}^{+}$lymphocytes than the nonresponder group and the nonvaccinated control group $\left(P=0.0001\right.$ and $P=0.011$ in $\left.\mathrm{CD} 4^{+} \mathrm{CD} 25^{+} \mathrm{Foxp}^{+}\right)$.

\section{Discussion and conclusion}

In this study, we evaluated the potential effects of engineered antitumor cell vaccine combined with gene silencing strategies. To this effect, we used 2'-OMe-PS-ASOs against Foxp3 and CTLA4 that are involved in Treg immunosuppressive effects. After tumor implantation in mice, we achieved 50\% and $20 \%$ survival employing an antitumor vaccine consisting of B16 GM-CSF genetically modified cells combined with anti-Foxp3 and anti-CTLA4 2'-OMe-PS-ASO, respectively. In contrast, no survival was observed in the control group.
These results are in agreement with an "in vitro" study in which Foxp3 gene silencing achieved a decrease in CTLA4 expression and an increase in antitumor immune response. ${ }^{26}$

For the "in vivo" experiment in this study, we used 2'-OMe-PS-ASO because we found the latter to be more effective than PPRH for CTLA4 and Foxp3 gene silencing "in vitro", due to difficulties in the penetration of PPRHs into the cells without a vector. In other studies, PPRHs have yielded good results when used with a vector in both "in vitro" and "in vivo" models. ${ }^{20-23}$ These results, considered globally, suggest that PPRH could be useful only with a carrier. Although 2'-OMe-PS-ASO and PPRH showed comparable blood concentration levels after peritoneal injection, PPRH performed much poorer than 2'-OMe-PS-ASO on cells in vitro. This could be due to the fact that PPRHs are larger and cell membrane barriers offer more strict size limitations 


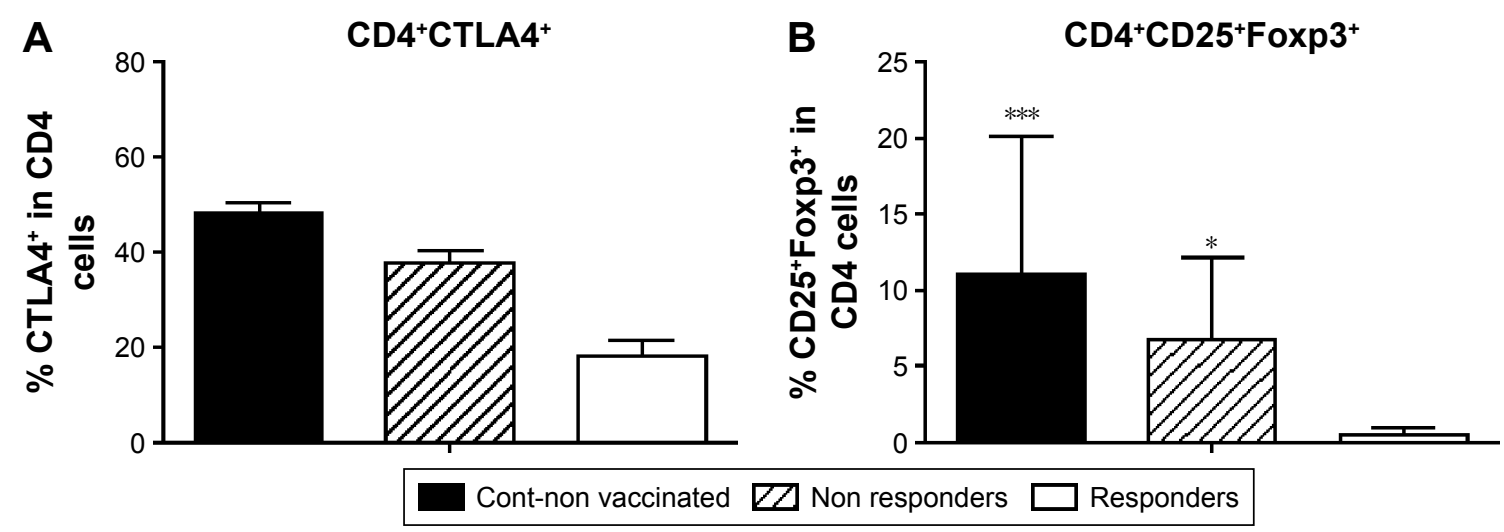

Figure 7 Comparison of CTLA4 and Foxp3 lymphocyte populations in the different vaccinated groups.

Notes: (A) Represents the percentage CTLA4+ cells from CD4 cells and (B) represents CD25+Foxp3+ from CD4 cells in the nonresponder group (mean), responder group, and control-nonvaccinated group. Statistically significant differences of each group versus the responder group were calculated using beta-regression, $* P=0.0 \mathrm{I} I$ and $* * * P=0.0088$.

than absorption by blood from a peritoneal injection. The dose of $2^{\prime}$-OMe-PS-ASO used in our study $(500 \mu \mathrm{g} / \mathrm{dose} / \mathrm{mouse})$ is consistent with the doses previously described in the literature. ${ }^{27-30}$ There are multiple clinical trials with ASOs, ${ }^{31-33}$ and two of them - fomivirsen and mipomersen - were approved by the FDA in 1998 and 2013, respectively. Parenteral administration of several ASOs has shown their clinical efficacy and was found to be well tolerated.

We observed a peak in CTLA4 and Foxp3 mRNA on days 2-4 and 11 after tumor implantation. The initial increase in Foxp3 mRNA (day 2) after tumor implantation seemed faster than that of CTLA4 mRNA (day 4). This could be due, at least in part, to the fact that CTLA4 gene expression is upregulated by Foxp3. ${ }^{34-39}$ Furthermore, we observed that, on day 4, CTLA4 and Foxp3 gene expression was greater in the mice that did not respond positively to the treatment than in those that responded positively. We think that initial increase of FoxP3 and CTLA4 mRNAs after tumor injection is related to the tumor tolerance onset and tumor progression. Thus, avoiding this early (days 2-4) increase in Foxp3 and CTLA4 expression could be crucial to avoid the tumor development. These results suggest that the early expression (day 4 after tumor implantation) of CTLA4 and Foxp3 is related to immunosuppression and tumor development. However, on day 11, lower Foxp3 and CTLA4 expression was observed in the mice that did not respond to the treatment. We do not know the reasons for this effect, though it could be due to the expression of CTLA4 in CD4-activated lymphocytes. On the other hand, since it has been shown that TCR stimulation can induce Foxp3 expression in FoxP3-CD4 ${ }^{+} \mathrm{T}$ cells without conferring suppressive activity, ${ }^{40-45}$ our results support the idea that the expression of CTLA4 and Foxp3 observed at day 11 might not be related to the presence of Treg.
Thus, Foxp3 seems to be necessary but not sufficient for Treg development.

In our experiments, the group vaccinated and treated with anti-CTLA4 2'-OMe-PS-ASO did not obtain the success recorded in other previous studies using GM-CSF producer B16 cells and anti-CTLA4 antibodies. ${ }^{46}$ This probably could be due to the different mechanisms of action of these blocking strategies. Recently, a study showed Treg depletion observed in the tumor infiltrate after anti-CTLA4 therapy to be mainly mediated by antibody-dependent cell cytotoxicity. ${ }^{47}$ In our study, treatment with anti-CTLA4 2'-OMe-PS-ASO blocked CTLA4 expression, but this did not deplete Treg cells - thus indicating that they can also mediate immunosuppression through other mechanisms alternative to CTLA4. ${ }^{48}$

The successful outcomes achieved in the group of animals vaccinated and treated with anti-Foxp3 2'-OMe-PS-ASO confirm Foxp3 as a key point in the immunosuppressive response mediated by Treg cells. Furthermore, these results suggest that Foxp3 gene silencing is a promising strategy in cancer treatment. Although we did not study the effect of ASOs used in our study on Foxp3 silencing in melanoma cells, other authors have shown that its reduced expression, employing a small interference Foxp3 plasmid transfection procedure, can delay tumor growth. ${ }^{19}$ According to these results, the systemic administration of ASOs could offer synergistic antitumor effects by acting on both lymphocytes and melanoma cells. In addition, a previous study using lentiviral vector codifying for shRNA showed Foxp3 to achieve tumor growth delay and prolong animal survival in a murine leukemia model. ${ }^{49}$ In our study, we improved those results, achieving up to $50 \%$ animal survival in the group vaccinated and treated with anti-Foxp3 2'-OMe-PS-ASO. Furthermore, we did not observe the characteristic adverse effects of 
treatment with anti-CTLA4 antibodies, ie, depigmentation, diarrhea, or weight loss, described in other studies..$^{50,51}$

On the other hand, we found an increase in $\mathrm{CD} 4^{+} \mathrm{CTLA} 4^{+}$ lymphocytes and classical Treg cells $\left(\mathrm{CD} 4^{+} \mathrm{CD} 25^{+} \mathrm{Foxp}^{+}\right)$ in animals that developed tumor, compared to those that did not develop tumor.

Our data support the notion that the lack of efficacy observed in therapeutic vaccinations is mainly associated to the expression of certain immunosuppressive genes. ${ }^{52,53}$ Also, we have found that combining gene silencing with antitumor therapeutic vaccination mediates synergistic effects, thus suggesting Treg response modulation by gene silencing to be an attractive alternative to the use of antibodies. Finally, although the silencing of Foxp3 is presented as a candidate of great interest in cancer treatment, new studies to increase the efficiency of silencing are needed in order to optimize the results obtained in our work.

\section{Acknowledgments}

This study was partially funded by the Spanish Ministry of Economy and Competitiveness (Project reference: SAF201127002 and SAF2011-23582). We thank the Central Research Unit of the Faculty of Medicine at the University of Valencia (Valencia, Spain) for granting technical support.

\section{Author contributions}

All authors contributed to data analysis, drafting, and critical revision of the paper, and accept accountability for all aspects of the work.

\section{Disclosure}

The authors report no conflicts of interest in this work.

\section{References}

1. Dunussi-Joannopoulos K, Dranoff G, Weinstein HJ, Ferrara JL, Bierer BE, Croop JM. Gene immunotherapy in murine acute myeloid leukemia: granulocyte-macrophage colony-stimulating factor tumor cell vaccines elicit more potent antitumor immunity compared with B7 family and other cytokine vaccines. Blood. 1998;91(1):222-230.

2. Small EJ, Sacks N, Nemunaitis J, et al. Granulocyte macrophage colony-stimulating factor-secreting allogeneic cellular immunotherapy for hormone-refractory prostate cancer. Clin Cancer Res. 2007;13(13):3883-3891.

3. Maio M, Fonsatti E, Lamaj E, et al. Vaccination of stage IV patients with allogeneic IL-4- or IL-2-gene-transduced melanoma cells generates functional antibodies against vaccinating and autologous melanoma cells. Cancer Immunol Immunother. 2002;51(1):9-14.

4. Salgia R, Lynch T, Skarin A, et al. Vaccination with irradiated autologous tumor cells engineered to secrete granulocyte-macrophage colony-stimulating factor augments antitumor immunity in some patients with metastatic non-small-cell lung carcinoma. J Clin Oncol. 2003;21(4):624-630.

5. Soiffer R, Hodi FS, Haluska F, et al. Vaccination with irradiated, autologous melanoma cells engineered to secrete granulocyte-macrophage colony-stimulating factor by adenoviral-mediated gene transfer augments antitumor immunity in patients with metastatic melanoma. J Clin Oncol. 2003;21(17):3343-3350.
6. Nemunaitis J, Sterman D, Jablons D, et al. Granulocyte-macrophage colony-stimulating factor gene-modified autologous tumor vaccines in non-small-cell lung cancer. J Natl Cancer Inst. 2004;96(4):326-331.

7. Zhang X, Shi X, Li J, et al. A novel therapeutic vaccine of mouse GM-CSF surface modified MB49 cells against metastatic bladder cancer. J Urol. 2012;187(3):1071-1079.

8. Moret-Tatay I, Díaz J, Marco FM, Crespo A, Aliño SF. Complete tumor prevention by engineered tumor cell vaccines employing nonviral vectors. Cancer Gene Ther. 2003;10(12):887-897.

9. Miguel A, Herrero MJ, Sendra L, et al. Comparative antitumor effect of preventive versus therapeutic vaccines employing B16 melanoma cells genetically modified to express GM-CSF and B7.2 in a murine model. Toxins. 2012;4(11):1058-1081.

10. Miguel A, Herrero MJ, Sendra L, et al. Comparative antitumor effect among GM-CSF, IL-12 and GM-CSF+IL-12 genetically modified tumor cell vaccines. Cancer Gene Ther. 2013;20(10):576-581.

11. Moret-Tatay I, Sanmartín I, Marco FM, Díaz J, Aliño SF. Nonviral therapeutic cell vaccine mediates potent antitumor effects. Vaccine. 2006; 24(18):3937-3945.

12. Guo C, Manjili MH, Subjeck JR, Sarkar D, Fisher PB, Wang XY. Therapeutic cancer vaccines: past, present, and future. Adv Cancer Res. 2013; 119:421-475.

13. Ise W, Kohyama M, Nutsch K, et al. CTLA-4 suppresses the pathogenicity of self antigen-specific $\mathrm{T}$ cells by cell-intrinsic and cell-extrinsic mechanisms. Nat Immunol. 2010;11(2):129-135.

14. Wing K, Yamaguchi T, Sakaguchi S. Cell-autonomous and nonautonomous roles of CTLA-4 in immune regulation. Trends Immunol. 2011;32(9):428-433.

15. Hodi FS, O'Day SJ, McDermott DF, et al. Improved survival with ipilimumab in patients with metastatic melanoma. NEngl J Med. 2010; 363(8):711-723.

16. Robert C, Thomas L, Bondarenko I, et al. Ipilimumab plus dacarbazine for previously untreated metastatic melanoma. $N$ Engl J Med. 2011; 364(26):2517-2526.

17. Josefowicz SZ, Lu LF, Rudensky AY. Regulatory T cells: mechanisms of differentiation and function. Annu Rev Immunol. 2012;30:531-564.

18. Wu Y, Borde M, Heissmeyer V, et al. FOXP3 controls regulatory T cell function through cooperation with NFAT. Cell. 2006;126(2): 375-387.

19. Franco-Molina MA, Miranda-Hernández DF, Mendoza-Gamboa E, et al. Silencing of Foxp3 delays the growth of murine melanomas and modifies the tumor immunosuppressive environment. Onco Targets Ther. 2016;9:243-253.

20. de Almagro MC, Coma S, Noé V, Ciudad CJ. Polypurine hairpins directed against the template strand of DNA knock down the expression of mammalian genes. J Biol Chem. 2009;284(17):11579-11589.

21. de Almagro MC, Mencia N, Noé V, Ciudad CJ. Coding polypurine hairpins cause target-induced cell death in breast cancer cells. Hum Gene Ther. 2011;22(4):451-463.

22. Rodríguez L, Villalobos X, Dakhel S, et al. Polypurine reverse Hoogsteen hairpins as a gene therapy tool against survivin in human prostate cancer PC3 cells in vitro and in vivo. Biochem Pharmacol. 2013;86(11): $1541-1554$.

23. Villalobos X, Rodríguez L, Prévot J, Oleaga C, Ciudad CJ, Noé V. Stability and immunogenicity properties of the gene-silencing polypurine reverse Hoogsteen hairpins. Mol Pharm. 2014;11(1):254-264.

24. Guillem VM, Tormo M, Revert F, et al. Polyethyleneimine-based immunopolyplex for targeted gene transfer in human lymphoma cell lines. J Gene Med. 2002;4(2):170-182.

25. Guillem, VM, Aliño SF. Transfection pathways of nonspecific and targeted PEI-polyplexes. Gene Ther Mol Biol. 2004;8:369-384.

26. Zhang HH, Fei R, Xie XW, et al. Specific suppression in regulatory T cells by Foxp3 siRNA contributes to enhance the in vitro anti-tumor immune response in hepatocellular carcinoma patients. Beijing Da Xue Xие Bao. 2009;41(3):313-318.

27. Ward AJ, Norrbom M, Chun S, Bennett CF, Rigo F. Nonsense-mediated decay as a terminating mechanism for antisense oligonucleotides. Nucleic Acids Res. 2014;42(9):5871-5879. 
28. Burdick AD, Sciabola S, Mantena SR, et al. Sequence motifs associated with hepatotoxicity of locked nucleic acid - modified antisense oligonucleotides. Nucleic Acids Res. 2014;42(8):4882-4891.

29. Yang B, Yu RL, Tuo S, et al. Antisense oligonucleotide against hTERT (Cantide) inhibits tumor growth in an orthotopic primary hepatic lymphoma mouse model. PLoS One. 2012;7(7):e41467.

30. Heemskerk H, de Winter C, van Kuik P, et al. Preclinical PK and PD studies on 2'-O-methyl-phosphorothioate RNA antisense oligonucleotides in the mdx mouse model. Mol Ther. 2010;18(6):1210-1217.

31. Gaudet D, Alexander VJ, Baker BF, et al. Antisense inhibition of apolipoprotein C-III in patients with hypertriglyceridemia. $N$ Engl J Med. 2015;373(5):438-447.

32. Sugihara C, Freemantle N, Hughes SG, Furniss S, Sulke N. The effect of $\mathrm{C}$-reactive protein reduction with a highly specific antisense oligonucleotide on atrial fibrillation assessed using beat-to-beat pacemaker Holter follow-up. J Interv Card Electrophysiol. 2015;43(1):91-98.

33. Büller HR, Bethune C, Bhanot $\mathrm{S}$, et al. Factor XI antisense oligonucleotide for prevention of venous thrombosis. N Engl J Med. 2015;372(3): $232-240$.

34. Gavin MA, Rasmussen JP, Fontenot JD, et al. Foxp3-dependent programme of regulatory T-cell differentiation. Nature. 2007;445(7129): $771-775$.

35. Hori S, Nomura T, Sakaguchi S. Control of regulatory T cell development by the transcription factor Foxp3. Science. 2003;299(5609): 1057-1061.

36. Marson A, Kretschmer K, Frampton GM, et al. Foxp3 occupancy and regulation of key target genes during T-cell stimulation. Nature. 2007; 445(7130):931-935.

37. Zheng Y, Josefowicz SZ, Kas A, Chu TT, Gavin MA, Rudensky AY. Genome-wide analysis of Foxp3 target genes in developing and mature regulatory T cells. Nature. 2007;445(7130):936-940.

38. Ono M, Yaguchi H, Ohkura N, et al. Foxp3 controls regulatory T-cell function by interacting with AML1/Runx1. Nature. 2007;446(7136): 685-689.

39. Wing K, Onishi Y, Prieto-Martin P, et al. CTLA-4 control over Foxp3+ regulatory T cell function. Science. 2008;322(5899):271-275.

40. Miyara M, Yoshioka Y, Kitoh A, et al. Functional delineation and differentiation dynamics of human CD4+ T cells expressing the FoxP3 transcription factor. Immunity. 2009;30(6):899-911.

41. Kmieciak M, Gowda M, Graham L, et al. Human T cells express CD25 and Foxp3 upon activation and exhibit effector/memory phenotypes without any regulatory/suppressor function. J Transl Med. 2009.22;7:89.

42. Allan SE, Crome SQ, Crellin NK, et al. Activation-induced FOXP3 in human $\mathrm{T}$ effector cells does not suppress proliferation or cytokine production. Int Immunol. 2007;19(4):345-354.
43. Gavin MA, Torgerson TR, Houston E, et al. Single-cell analysis of normal and FOXP3-mutant human T cells: FOXP3 expression without regulatory T cell development. Proc Natl Acad Sci US A. 2006;103(17): 6659-6664.

44. Tran DQ, Ramsey H, Shevach EM. Induction of FOXP3 expression in naive human CD4+FOXP3 $\mathrm{T}$ cells by $\mathrm{T}$-cell receptor stimulation is transforming growth factor-beta dependent but does not confer a regulatory phenotype. Blood. 2007;110(8):2983-2990.

45. Wang J, Ioan-Facsinay A, van der Voort EI, Huizinga TW, Toes RE. Transient expression of FOXP3 in human activated nonregulatory CD4+ T cells. Eur J Immunol. 2007;37(1):129-138.

46. van Elsas A, Hurwitz AA, Allison JP. Combination immunotherapy of B16 melanoma using anti-cytotoxic T lymphocyte-associated antigen 4 (CTLA-4) and granulocyte/macrophage colony-stimulating factor (GM-CSF)-producing vaccines induces rejection of subcutaneous and metastatic tumors accompanied by autoimmune depigmentation. J Exp Med. 1999;190(3):355-366.

47. Simpson TR, Li F, Montalvo-Ortiz W, et al. Fc-dependent depletion of tumor-infiltrating regulatory $\mathrm{T}$ cells co-defines the efficacy of anti-CTLA-4 therapy against melanoma. J Exp Med. 2013;210(9): $1695-1710$.

48. Sutmuller RP, van Duivenvoorde LM, van Elsas A, et al. Synergism of cytotoxic $\mathrm{T}$ lymphocyte-associated antigen 4 blockade and depletion of $\mathrm{CD} 25(+)$ regulatory $\mathrm{T}$ cells in antitumor therapy reveals alternative pathways for suppression of autoreactive cytotoxic $\mathrm{T}$ lymphocyte responses. J Exp Med. 2001;194(6):823-832.

49. Tsai BY, Suen JL, Chiang BL. Lentiviral-mediated Foxp3 RNAi suppresses tumor growth of regulatory $\mathrm{T}$ cell-like leukemia in a murine tumor model. Gene Ther. 2010;17(8):972-979.

50. Gregor PD, Wolchok JD, Ferrone CR, et al. CTLA-4 blockade in combination with xenogeneic DNA vaccines enhances T-cell responses, tumor immunity and autoimmunity to self antigens in animal and cellular model systems. Vaccine. 2004;22(13-14):1700-1708.

51. Phan GQ, Yang JC, Sherry RM, et al. Cancer regression and autoimmunity induced by cytotoxic T lymphocyte-associated antigen 4 blockade in patients with metastatic melanoma. Proc Natl Acad Sci US A. 2003;100(14):8372-8377.

52. Pardoll DM. The blockade of immune checkpoints in cancer immunotherapy. Nat Rev Cancer. 2012;12(4):252-264.

53. Mocellin S, Nitti D. Therapeutics targeting tumor immune escape: towards the development of new generation anticancer vaccines. Med Res Rev. 2008;28(3):413-444.
OncoTargets and Therapy

\section{Publish your work in this journal}

OncoTargets and Therapy is an international, peer-reviewed, open access journal focusing on the pathological basis of all cancers, potential targets for therapy and treatment protocols employed to improve the management of cancer patients. The journal also focuses on the impact of management programs and new therapeutic agents and protocols on

\section{Dovepress}

patient perspectives such as quality of life, adherence and satisfaction The manuscript management system is completely online and includes a very quick and fair peer-review system, which is all easy to use. Visit http://www.dovepress.com/testimonials.php to read real quotes from published authors. 